\title{
ABSORÇ̃̃O E ACÚMULO DE CÁDMIO E SEUS EFEITOS SOBRE O CRESCIMENTO RELATIVO DE PLANTAS DE AGUAPÉ E DE SALVÍNIA ${ }^{1}$
}

\author{
JURACI ALVES DE OLIVEIRA ${ }^{2}$, JOSÉ CAMBRAIA ${ }^{3}$, MARCO ANTONIO OLIVA \\ CANO $^{4}$ E CLÁUDIO PEREIRA JORDÃO 5
}

Departamento de Biologia Geral, Universidade Federal de Viçosa, 36.501-000 - Viçosa, MG.

\begin{abstract}
RESUMO - A absorção e acúmulo de Cd e seus efeitos sobre o crescimento relativo foram estudados em aguapé (Eichhornia crassipes (Mart.) Solms) e salvínia (Salvinia auriculata Aubl.), em solução nutritiva. $\mathrm{O}$ aguapé absorveu quantidade significativamente maior de $\mathrm{Cd}$ do que a salvínia, tendo a diferença aumentado com o tempo de exposição ao $\mathrm{Cd}$. $\mathrm{O} \mathrm{Km}$ da absorção de $\mathrm{Cd}$, estatisticamente igual nas duas espécies aquáticas quando as folhas contatavam a solução nutritiva, tornou-se maior em salvínia quando se impediu fisicamente que as folhas contatassem a solução de absorção. O Vmax de absorção de Cd, por outro lado, foi sempre maior em salvínia, independentemente do contato ou não das folhas com a solução nutritiva. A quantidade de $\mathrm{Cd}$ adsorvido e absorvido aumentou com a elevação da concentração de $\mathrm{Cd}$ na solução de cultivo, nas duas espécies estudadas, tendo sido maior em salvínia, possivelmente em razão da participação da parte aérea no processo de absorção. $\mathrm{O}$ acúmulo de $\mathrm{Cd}$ nas plantas, elevado nas primeiras $12 \mathrm{~h}$ de exposição, decresceu rapidamente com o tempo de exposição, estabilizando após três dias de exposição. Salvínia apresentou maior acúmulo diário de $\mathrm{Cd}$ por unidade de peso mas aguapé maior acúmulo total por unidade experimental. Os teores de $\mathrm{Cd}$ aumentaram com o aumento do tempo de exposição e da concentração de $\mathrm{Cd}$ na solução nutritiva, nas duas partes da planta das duas espécies, especialmente nas raízes. Cerca de $80 \%$ de todo o Cd absorvido acumulou-se nas raízes de aguapé, e a distribuição não foi afetada pelo contato das folhas com a solução nutritiva. Em salvínia, quando se impediu o contato das folhas com a solução nutritiva observou-se uma distribuição do $\mathrm{Cd}$ aproximadamente igual à de aguapé. Quando, porém, se permitiu o contato das folhas com a solução nutritiva a parte aérea passou a contribuir com quase $50 \%$ do $\mathrm{Cd}$ absorvido. As taxas de crescimento relativo decresceram intensamente com o aumento da concentração de $\mathrm{Cd}$ na solução nutritiva nas duas espécies aquáticas, especialmente em salvínia. As concentrações de Cd para promover redução de $25 \%$ no crescimento relativo foram, em média, doze vezes menores em salvínia do que em aguapé, em razão de sua maior sensibilidade a este metal pesado.
\end{abstract}

TERMOS ADICIONAIS PARA INDEXAÇÃO: Metais pesados, tolerância a cádmio, plantas aquáticas

Recebido: 10/10/2001 - Aceito: 12/12/2001

1. Parte da Tese de Doutorado defendida pelo primeiro autor na Universidade Federal de Viçosa. Trabalho financiado parcialmente pela FAPEMIG.

2. Professor Adjunto, DS, Departamento de Biologia Geral, UFV.E-mail: jalves@ufv.br

3. Professor Titular, PhD, Departamento de Biologia Geral, UFV. Bolsista do CNPq.

4. Professor Titular, Dr rer. Nat., Departamento de Biologia Vegetal, UFV. Bolsista do CNPq.

5. Professor Titular, PhD, Departamento de Química, UFV. Bolsista do CNPq. 


\title{
CADMIUM ABSORPTION AND ACCUMULATION AND ITS EFFECTS ON THE RELATIVE GROWTH OF WATER HYACINTHS AND SALVINIA
}

\begin{abstract}
SUMMARY - Cadmium absorption and accumulation and its effects on the relative growth of water hyacinth (Eichhornia crassipes (Mart.) Solms) and salvinia (Salvinia auriculata Aubl.) in nutrient solution were studied. Water hyacinth absorbed a significant higher amount of Cd than salvinia, and the difference between the species increased with the time of $\mathrm{Cd}$ treatment. The $\mathrm{Km}$ of Cd absorption, statistically similar in the two aquatic species when the leaves contacted the nutrient solution, became larger in salvinia when the leaves were not allowed to contact the absorption solution. The Vmax, on the other hand, was always larger in salvinia, independent of the contact or not of the leaves with the nutrient solution. The amount of adsorbed and absorbed $\mathrm{Cd}$ increased with the increase of $\mathrm{Cd}$ concentration, in both species, especially in salvinia, probably due to leaf contribution to uptake. The accumulation of $\mathrm{Cd}$ in the plants, high in the first $12 \mathrm{~h}$, quickly decreased with the time of exposition to $\mathrm{Cd}$, reaching stabilization after three days. Salvinia showed larger daily accumulation of $\mathrm{Cd}$ per unit of weight but water hyacinth larger total accumulation per experimental unit. Cadmium content increased with the increase in the time of treatment and with Cd concentration in the nutrient solution, in both parts of the plant of the two species, especially in the roots. In water hyacinth about $80 \%$ of the total absorbed Cd accumulated in the roots, and that distribution did not change with the contact of the leaves with the nutrient solution. In salvinia, when the contact of the leaves with the nutrient solution was not allowed Cd distribution was similar to that observed in water hyacinth. When, however, the leaves contacted the nutrient solution about $50 \%$ of the absorbed $\mathrm{Cd}$ accumulated in that part of the plant. The relative growth decreased intensely with the increase in $\mathrm{Cd}$ concentration in both aquatic species, especially in salvinia. The concentration of $\mathrm{Cd}$ to reduce $25 \%$ in the relative growth rate was, on average, twelve times smaller in salvinia than in water hyacinth, due to its sensitivity to this heavy metal.
\end{abstract}

ADDITIONAL INDEX TERMS: Heavy metals, cadmium tolerance, aquatic plants

\section{INTRODUÇÃO}

Dentre as várias formas de contaminação do meio ambiente resultante das diversas atividades industriais e agrícolas, a contaminação da água com metais pesados tem sido uma das que tem trazido mais preocupação aos pesquisadores e órgãos governamentais envolvidos no controle de poluição. É que a água, além de ser um dos mais importantes fatores da preservação da vida em vias de se tornar escassa no mundo, está sendo contaminada com o despejo de rejeitos industriais e urbanos e várias outras atividades humanas.

Há, portanto, grande interesse não somente em se detectar possíveis contaminações como, também, encontrar meios que possibilitem a descontaminação do meio ambiente. Várias plantas aquáticas têm sido estudadas e sugeridas como alternativas para solução destes problemas. Dentre elas, o aguapé (Eichhornia crassipes (Mart.) Solms), que apresenta elevada capacidade de absorver e tolerar elevadas quantidades de íons de metais pesados (Muramoto e Oki, 1983) é uma das mais promissoras. Outra espécie que apresenta potencial de uso em estudos relacionados à poluição aquática por metais pesados é a salvínia (Salvinia auriculata Aubl.). Esta, entretanto, ao contrário da primeira, apresenta sensibilidade relativamente elevada tornando-a, potencialmente interessante na indicação de contaminação de sistemas aquáticos com metais pesados (Outridge e Hutchinson, 1990).

As espécies vegetais, de modo geral, apresentam grande variação quanto à absorção de metais pesados, incluindo o Cd (Hart et al., 1998). 
As raízes, geralmente, constituem o principal órgão da planta envolvido na absorção e, portanto, quase sempre, as maiores concentrações de metais pesados são, também, encontradas nesta parte da planta (Grant et al., 1998). Em plantas aquáticas, entretanto, as folhas estabelecem contato direto com a solução de absorção que contem o metal pesado e, portanto, teoricamente podem absorver tanto quanto as raízes. A absorção de metais pesados por folhas é pouco conhecida e, menos ainda, a influência que isto teria sobre a absorção pelas raízes e a subseqüente translocação para a parte aérea (Cakmak et al., 2000).

Este trabalho, portanto, teve como objetivo avaliar a absorção, o acúmulo e a distribuição de Cd e seu subseqüente efeito sobre o crescimento relativo em aguapé e salvínia

\section{MATERIAL E MÉTODOS}

\section{Obtenção e adaptação das plantas}

Plantas aquáticas das espécies Eichhornia crassipes (Mart.) Solms e Salvinia auriculata Aubl., coletadas em várias represas da Universidade Federal de Viçosa, Viçosa, MG, que não recebiam qualquer despejo de poluentes, foram utilizadas em todos os experimentos.

As plantas, após selecionadas quanto à uniformidade de tamanho e forma, foram lavadas por $1 \mathrm{~min}$ em solução de hipoclorito de sódio $1 \%(\mathrm{v} / \mathrm{v})$ e em água corrente e mantidas por 24 horas em água desmineralizada. Após esse período, foram transferidas para recipientes de polietileno com $10 \mathrm{~L}$ de solução nutritiva de Hoagland (Hoagland e Arnon, 1950), $\mathrm{n}^{\circ} .1$, com 1/5 da força iônica original, $\mathrm{pH}$, e colocadas em sala de crescimento com temperatura e luminosidade controladas $\left(25 \pm 2^{\circ} \mathrm{C}, 230 \mu \mathrm{mol} \quad \mathrm{s}^{-1} \mathrm{~m}^{-2}\right), \quad$ sob fotoperíodo de 16 horas, onde permaneceram por três dias, em período de adaptação.

\section{Avaliação das constantes cinéticas de absorção de Cd}

As plantas das duas espécies, após o período de adaptação, foram transferidas para vasos de polietileno contendo $1 \mathrm{~L}$ da solução nutritiva de Hoagland $n^{\circ}$. 1, com $1 / 5$ da força iônica original, $\mathrm{pH} 7,0$, na ausência e na presença de $\mathrm{Cd}$ na concentração de $5 \mu \mathrm{M}$, na forma de $\mathrm{Cd}\left(\mathrm{NO}_{3}\right)_{2} \cdot 4 \mathrm{H}_{2} \mathrm{O}$. Após a introdução das plantas na solução de absorção, em que se teve o cuidado de impedir o contato das folhas com a solução nutritiva em metade dos vasos, alíquotas de $1 \mathrm{~mL}$ passaram a ser retiradas de cada vaso, inicialmente, de $15 \mathrm{em} 15 \mathrm{~min}$ durante a primeira hora, de $30 \mathrm{em}$ 30 min durante a segunda hora e, em seguida, de hora em hora até que não houvesse mudança significativa na concentração de $\mathrm{Cd}$ da solução nutritiva. As concentrações de $\mathrm{Cd}$ nas alíquotas coletadas foram, então, determinadas por espectrofotometria de absorção atômica, sendo os dados obtidos utilizados para estimar as constantes cinéticas, por uma aproximação gráficomatemática, conforme sugerido por Ruiz (1985). Ao final do ensaio, as plantas foram divididas em raízes e parte aérea para determinação do peso de matéria seca e dos teores de Cd nas duas partes da planta.

\section{Avaliação da adsorção e dessorção do Cd pelas raízes}

As plantas das duas espécies, após o período de adaptação, foram transferidas para vasos de polietileno com $500 \mathrm{~mL}$ da solução nutritiva de Hoagland $\mathrm{n}^{\circ} .1$, com $1 / 5$ da força iônica original, $\mathrm{pH} 7,0$, isenta de $\mathrm{Ca}^{2+}$, contendo $\mathrm{Cd}$ nas concentrações de 5 e $10 \mu \mathrm{M}$, onde permaneceram por $30 \mathrm{~min}$. Após esse período, as plantas foram removidas da solução nutritiva, lavadas em água desmineralizada, sob agitação magnética por 30 segundos, e, então, transferidas para vasos de polietileno contendo $500 \mathrm{~mL}$ de uma solução de $\mathrm{Ca}\left(\mathrm{NO}_{3}\right)_{2} \quad 1,25 \mathrm{mM}$. Esta solução foi trocada, a cada $10 \mathrm{~min}$, durante um período de $60 \mathrm{~min}$. Nas soluções coletadas determinou-se o teor de $\mathrm{Cd}$ por espectrofotometria de absorção atômica. Ao final do período de dessorção, as plantas foram lavadas, separadas em raízes e parte aérea e secadas em estufa convencional a $80^{\circ} \mathrm{C}$ até a obtenção de peso seco constante e, após mineralização, determinouse a quantidade de $\mathrm{Cd}$ absorvida. 
Oliveira et al.

Efeito de diferentes níveis de Cd e tempo de exposição sobre os teores $\mathrm{Cd}$ e sobre o crescimento relativo.

As plantas das duas espécies, após o período de adaptação, foram transferidas para vasos de polietileno contendo $2 \mathrm{~L}$ de solução nutritiva de Hoagland $\mathrm{n}^{\circ} .1$, com $1 / 5$ da força iônica original, $\mathrm{pH} 7,0$, onde foram tratadas com diferentes concentrações de Cd: $0 ; 1,0 ; 2,5 ; 5,0$; 10,0 ; e $20,0 \mu \mathrm{M}$, fornecido sempre na forma de $\mathrm{Cd}\left(\mathrm{NO}_{3}\right)_{2} \cdot 4 \mathrm{H}_{2} \mathrm{O}$, durante um período de 10 dias. A solução nutritiva foi trocada no quinto dia e o pH ajustado diariamente para 7,0 . O peso inicial de matéria seca foi estimado a partir de amostras tomadas ao acaso do mesmo lote de plantas utilizadas no experimento.

Num segundo experimento paralelo, plantas das duas espécies, preparadas exatamente conforme anteriormente descrito, foram tratadas com $\mathrm{Cd}$ na concentração de $5 \mu \mathrm{M}$ durante 12 horas, 3, 5 e 10 dias. Neste caso, a solução nutritiva foi trocada diariamente, a fim de manter aproximadamente constante o valor de $\mathrm{pH}$ e da concentração de $\mathrm{Cd}$.

No décimo dia, quando o primeiro experimento foi encerrado ou após cada período de exposição no segundo experimento, o material vegetal foi colhido e lavado em água corrente, em solução de $\mathrm{HCl} 0,1 \mathrm{M}$ por 1 min e, em seguida, enxaguadas em água desmineralizada. Após determinação do peso de matéria fresca, o material vegetal foi colocado para secar em estufa convencional a $80^{\circ} \mathrm{C}$ até obtenção de peso seco constante. Na matéria seca foram determinados os teores de $\mathrm{Cd}$ nas raízes e na parte aérea.

As taxas de crescimento relativo foram estimadas, utilizando-se a equação proposta por Hunt (1978).

\section{Determinação do Teor de Cádmio}

O material vegetal, moído em almofariz elétrico em cápsula de aço inox, foi submetido à mineralização por via úmida, usando-se uma mistura nítrico-perclórica e os teores de cádmio determinados por espectrofotometria de absorção atômica (Allan, 1969).

\section{Delineamento experimental}

Todos os experimentos foram realizados no delineamento experimental de blocos casualizados, segundo um esquema fatorial. Os resultados obtidos foram submetidos à análise de variância e as médias foram comparadas pelo teste $\mathrm{F}$.

\section{RESULTADOS E DISCUSSÃO}

\section{Absorção e adsorção de Cd}

As plantas de aguapé, na mesma base de peso, retiraram uma quantidade de $\mathrm{Cd}$ significativamente maior do que as de salvínia, diferença esta que se ampliou com o tempo de exposição a este elemento (Figura 1). Esta diferença já era esperada em função da toxicidade do $\mathrm{Cd}$ e das diferenças de tolerância destas duas plantas a este elemento. Evidentemente que, quanto maior o tempo de exposição das plantas ao $\mathrm{Cd}$ maiores são os danos sobre seus sistemas metabólicos, incluindo a produção de energia e, ou sobre a síntese das proteínas formadoras do canal iônico através do qual o Cd está penetrando nas células.

As constantes cinéticas da absorção de Cd pelas duas espécies são apresentadas na Tabela 1. Os valores de $\mathrm{Km}$ foram estatisticamente iguais nas duas espécies aquáticas quando se permitiu que houvesse contato das folhas com a solução de absorção. Quando se impediu fisicamente que as folhas tocassem a solução de absorção, observou-se um aumento de cerca de $18 \%$ no valor do $\mathrm{Km}$ em salvínia, enquanto em aguapé o valor permaneceu essencialmente constante. Sob esta condição, portanto, as raízes de aguapé apresentaram um valor de $\mathrm{Km}$ menor, isto é, maior afinidade por $\mathrm{Cd}$, do que as de salvínia. Esta perda de afinidade do sistema de absorção de $\mathrm{Cd}$, que ocorreu apenas em salvínia, sugere que o sistema de absorção nas folhas tem uma afinidade por $\mathrm{Cd}$ ligeiramente maior do que as raízes. 


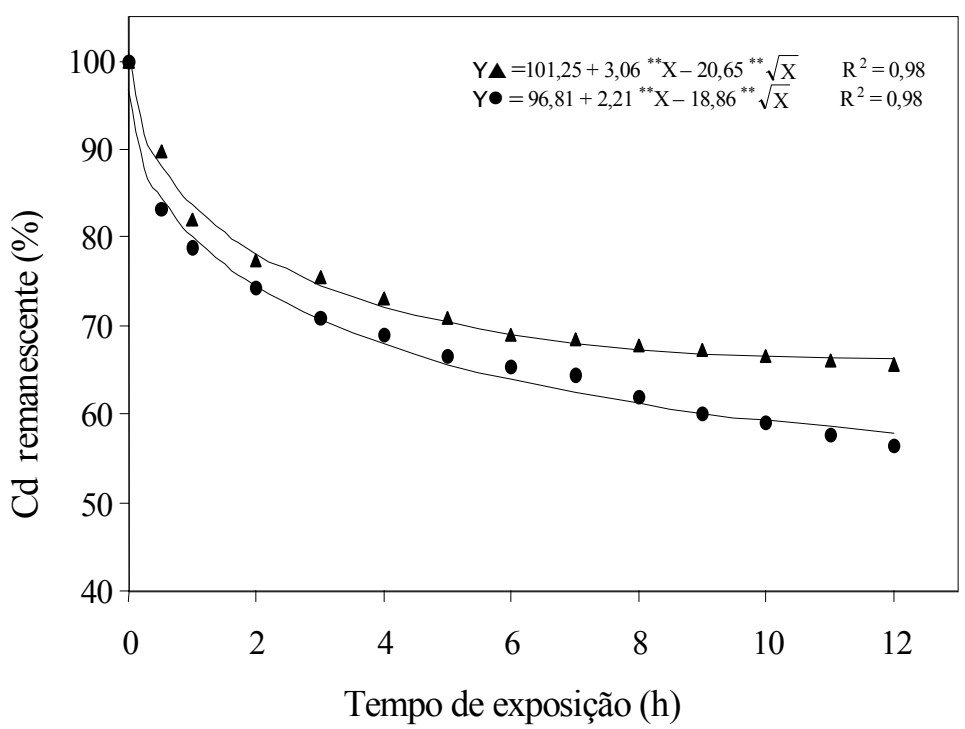

FIGURA 1 - Efeito do tempo de exposição sobre a absorção de Cd por aguapé ( ○ ) e salvínia ( expostas a uma solução de cultivo contendo $\mathrm{Cd}$ na concentração de $5 \mu \mathrm{M}$.

A velocidade máxima de absorção (Vmax) de $\mathrm{Cd}$ em salvínia foi quase 2,5 vezes maior do que em aguapé quando se permitiu o contato das folhas com a solução de absorção (Tabela 1). Quando se impediu fisicamente que as folhas tocassem a solução de absorção o valor de Vmax permaneceu inalterado em aguapé, mas reduziu cerca de $23 \%$ em salvínia. Mesmo assim, o valor de Vmax em salvínia ainda foi cerca de $85 \%$ superior ao valor determinado em aguapé.

No caso do aguapé o contato ou não das folhas com a solução absorção não alterou os valores de $\mathrm{Km}$ e de Vmax, indicando que as folhas não têm participação direta no processo de absorção. Nessa espécie, em razão da presença de estruturas que favorecem sua flutuação na água e da distribuição de suas folhas, mesmo em condições naturais, o contato das folhas com a solução de cultivo é muito pequeno e, portanto, a participação das folhas na absorção de íons do meio de nutrição deve, também, ser pequena. Nas plantas de salvínia, ao contrário, a maior parte da face adaxial das folhas entra em contato com a solução de absorção contendo $\mathrm{Cd}$ e parece haver uma participação significativa desta parte da planta na absorção deste elemento. Nestas plantas, portanto, como Vmax foi calculado com base apenas na massa de raízes, é possível que tenha havido uma superestimativa de seu valor.

Outro complicador na avaliação da absorção e, ou estimativa de constantes cinéticas de absorção de elementos como o $\mathrm{Cd}$ é a fitoxicidade inerente do próprio elemento. Como este elemento é extremamente tóxico, interferindo fortemente no metabolismo da planta e na biossíntese dos sistemas de transporte de íons, não se pode esperar muito tempo para efetuar a avaliação da absorção. Assim, para se reduzir tal efeito, optou-se por avaliar as constantes cinéticas em plantas em "steady state", exceto com relação à concentração de $\mathrm{Cd}$.

Em aguapé, sob condições experimentais semelhantes, observou-se decréscimo acentuado dos níveis de $\mathrm{Cd}$ na solução de cultivo nas primeiras $3 \mathrm{~h}$ de exposição, seguido de taxa aproximadamente linear de decréscimo até $12 \mathrm{~h}$, sendo que essa fase de lenta absorção corresponde à absorção intracelular (Fett et al., 1994). 
Aparentemente, a capacidade de manter essa fase por tempo prolongado depende da capacidade das raízes de sintetizar fitoquelatinas, as quais têm sido identificadas em várias espécies de plantas (Rauser, 1986; Obata e Umebayashi, 1986), incluindo aguapé (Fujita e Kawanishi, 1986) e Salvinia minima (Outridge et al., 1991).

A quantidade de $\mathrm{Cd}$ adsorvido por grama de matéria seca de raiz aumentou,em média, cerca de $123 \%$ com a elevação da concentração de $\mathrm{Cd}$ na solução de cultivo, nas duas espécies aquáticas estudadas (Tabela 2). As raízes de salvínia, independente da concentração de $\mathrm{Cd}$ na solução de cultivo, adsorveram, em média, cerca de 4 vezes mais $\mathrm{Cd}$ do que as de aguapé. Como a quantidade adsorvida foi avaliada com base na concentração de Cd presente na solução de dessorção e não pela análise dos tecidos vegetais, propriamente dito, é possível que esse valor esteja sendo superestimado em razão de uma possível absorção foliar.

TABELA 1 - Constantes cinéticas da absorção de $\mathrm{Cd}^{2+}$ em plantas de aguapé e salvínia, permitindo-se ou não o contato das folhas com a solução de absorção.

\begin{tabular}{|c|c|c|c|c|}
\hline \multirow{2}{*}{$\begin{array}{l}\text { Contato das folhas } \\
\text { com a solução de } \\
\text { absorção }\end{array}$} & \multicolumn{2}{|c|}{$\mathrm{Km}$} & \multicolumn{2}{|c|}{ Vmax } \\
\hline & Aguapé & Salvínia & Aguapé & Salvínia \\
\hline & \multicolumn{2}{|c|}{$\mu m o l L^{-1}$} & \multicolumn{2}{|c|}{ umol $L^{-1} g^{-1} M S$} \\
\hline Sim & $4,04 \mathrm{Aa}^{1}$ & 4,19 Ba & $4,26 \mathrm{Ab}$ & $10,44 \mathrm{Aa}$ \\
\hline Não & $3,94 \mathrm{Ab}$ & 4,65 Aa & $4,32 \mathrm{Ab}$ & 7,99 Ba \\
\hline
\end{tabular}

${ }^{1}$ As médias seguidas pelas mesmas letras maiúsculas nas colunas, para cada espécie, e minúsculas nas linhas, para cada tratamento, não diferem estatisticamente entre si, pelo teste $\mathrm{F}$, a 5\% de probabilidade.

TABELA 2 - Adsorção e absorção de Cd por raízes de aguapé e salvínia expostas a dois níveis de Cd durante 30 minutos

\begin{tabular}{|c|c|c|c|c|c|c|}
\hline \multirow{2}{*}{$\mathrm{Cd}$} & \multicolumn{2}{|c|}{ Cd adsorvido } & \multicolumn{2}{|c|}{ Cd absorvido } & \multicolumn{2}{|c|}{ Cd adsorvido/absorvido } \\
\hline & Aguapé & Salvínia & Aguapé & Salvínia & Aguapé & Salvínia \\
\hline$\mu M^{l}$ & \multicolumn{4}{|c|}{$\mu g g^{-1} M S$} & & \\
\hline 5,0 & $211,3 \mathrm{Aa}^{1}$ & $832,9 \mathrm{Ab}$ & $86,3 \mathrm{Aa}$ & $328,8 \mathrm{Ab}$ & 2,5 $\mathrm{Aa}$ & $2,5 \mathrm{Aa}$ \\
\hline 10,0 & $471,7 \mathrm{Ba}$ & $1873,3 \mathrm{Bb}$ & $186,4 \mathrm{Ba}$ & $233,0 \mathrm{Bb}$ & 2,6 Aa & $8,0 \mathrm{Bb}$ \\
\hline
\end{tabular}

${ }^{1}$ As médias seguidas pelas mesmas letras maiúsculas nas colunas, para cada espécie, e minúsculas nas linhas, para cada tratamento, não diferem estatisticamente entre si, pelo teste $\mathrm{F}$, a $5 \%$ de probabilidade. 
$\mathrm{Na}$ concentração de $5 \mu \mathrm{M}$ de $\mathrm{Cd}$ na solução nutritiva, as plantas de salvínia, também, absorveram aproximadamente 4 vezes mais $\mathrm{Cd}$ do que as de aguapé, tornando a relação $\mathrm{Cd}$ adsorvido/absorvido essencialmente igual à de plantas de aguapé. Na concentração de $10 \mu \mathrm{M}$ de $\mathrm{Cd}$, no entanto, embora a quantidade de $\mathrm{Cd}$ adsorvido por salvínia tenha aumentado, observouse drástica diminuição na quantidade absorvida, ficando a relação $\mathrm{Cd}$ adsorvido/absorvido em salvínia apenas cerca 3,1 vezes superior à em aguapé. Isso, provavelmente, se deveu aos efeitos tóxicos do $\mathrm{Cd}$ sobre o metabolismo daquela planta ou diretamente sobre seu sistema de transporte de $\mathrm{Cd}$ através membrana plasmática (Gupta e Devi, 1992), aparentemente bem mais sensível que o aguapé.

Aparentemente, mesmo na concentração mais elevada de $\mathrm{Cd}$, parece não ter ocorrido saturação dos sítios de adsorção do espaço livre de Donnan, uma vez que a fração trocável mais do que dobrou com a duplicação da concentração de $\mathrm{Cd}$ na solução de cultivo. Resultados semelhantes foram obtidos por Fett et al. (1994), que demonstraram a enorme capacidade de acúmulo de $\mathrm{Cd}$ apresentada por aguapé, que concentraram em seus tecidos mais que 2,29 mg de Cd trocável por grama de matéria seca.
Os resultados mostram, também, que no caso de íons como o $\mathrm{Cd}^{2+}$, uma parte significativa do elemento retirado da solução nutritiva está apenas adsorvido e não realmente absorvido. Com o prolongamento do período de exposição, entretanto, a fração absorvida tende a aumentar, dependente do grau de toxicidade do elemento, enquanto a fração adsorvida tende a atingir um patamar.

\section{Acúmulo e distribuição do Cd}

$\mathrm{O}$ acúmulo de $\mathrm{Cd}$ nas plantas, ainda bastante elevado após 12 horas de exposição, decresceu rapidamente com o tempo de exposição das plantas a esse elemento, tanto nas raízes como na parte aérea das duas espécies aquáticas analisadas (Figura 2). Após três dias, o acúmulo continua decrescendo, mas em taxa muito menor, tendendo para uma estabilização até o final do período experimental, nas duas espécies. A exposição de plantas a níveis tóxicos de elementos como o $\mathrm{Cd}$ resultam em rápido declínio na capacidade das plantas absorverem e, ou acumularem este elemento, principalmente em função de uma redução generalizada nas taxas metabólicas do vegetal.

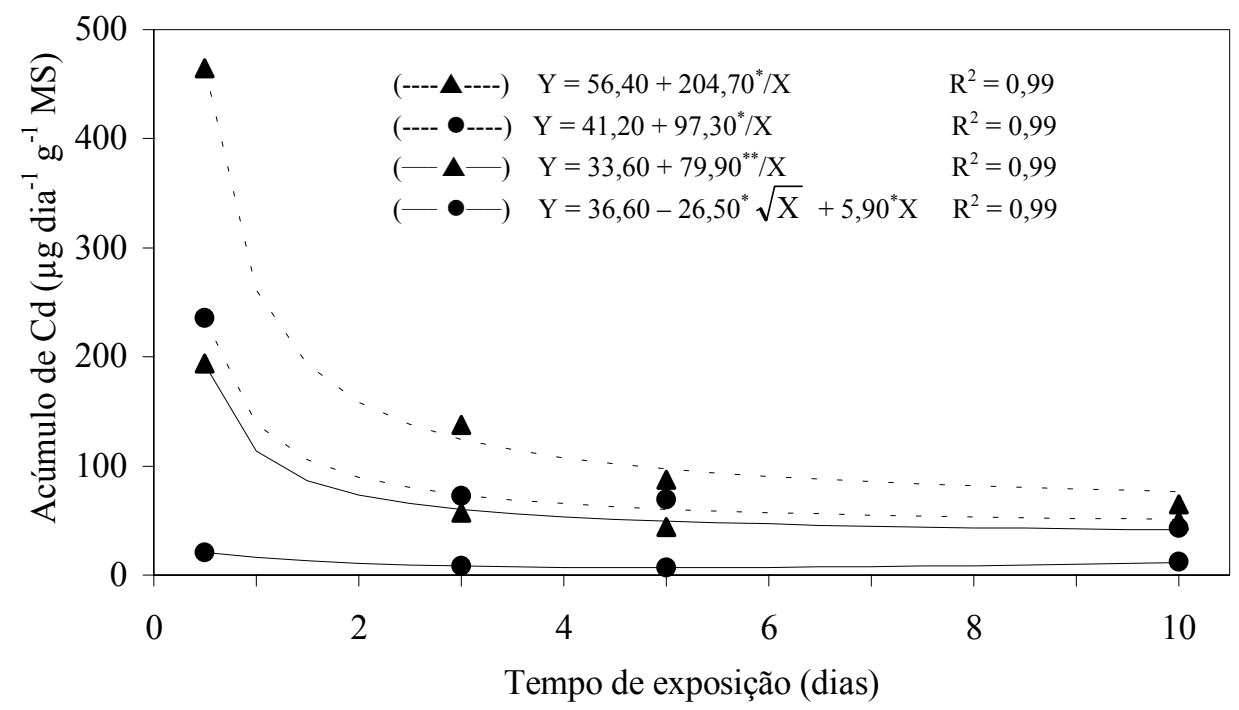

FIGURA 2 - Acúmulo de Cd por raízes ( $\boldsymbol{\Delta}$ ) e parte aérea ( $\bullet$ ) de aguapé $(-)$ e salvínia (----) em função do tempo de exposição a uma solução de cultivo contendo Cd na concentração de $5 \mu \mathrm{M}$. 
Como neste experimento, a exposição ao $\mathrm{Cd}$ se prolongou por um período de tempo relativamente longo os efeitos tóxicos do metal sobre o metabolismo vegetal tornaram-se evidentes pelo rápido declínio da taxa de acúmulo diário. Observe que as folhas de salvínia, após 12 horas, apresentavam um acúmulo de $\mathrm{Cd}$ mais de 2,4 vezes superior às de aguapé. No caso da salvínia, provavelmente, o $\mathrm{Cd}$ encontrado nas folhas parte resultou de translocação radicular mas parte significativa pode ter sido resultado de uma absorção direta pelas folhas que entram em contato com a solução nutritiva. Em aguapé, por outro lado, acredita-se que o $\mathrm{Cd}$ presente nas folhas originou-se essencialmente de translocação radicular.

Observe que o acúmulo diário de $\mathrm{Cd}$ por unidade de peso foi sempre maior em salvínia do que em aguapé, independente da parte analisada (Figura 2). Como no planejamento experimental optou-se por colocar plantas em número suficiente para cobrir a área de lâmina d'água dos vasos e não um número fixo de plantas as massas das plantas das duas espécies eram bastante distintas. Os acúmulos diários totais de $\mathrm{Cd}$ de todas as plantas da unidade experimental mostraram curvas similares mas, neste caso, o aguapé passou a acumular significativamente mais $\mathrm{Cd}$ do que a salvínia (resultados não apresentados). O aguapé, portanto, para uma definida área de lâmina d'água produz maior quantidade de massa vegetal e, sendo mais tolerante a níveis elevados de metais pesados, possui maior capacidade de remover estes metais pesados de águas contaminadas.

$\mathrm{O}$ teor de $\mathrm{Cd}$ aumentou tanto nas raízes como na parte aérea das duas espécies aquáticas em função do tempo de exposição ao Cd (Figura $3)$, tendo sido significativamente maior em salvínia, durante todo o período experimental. No caso de aguapé, o teor de $\mathrm{Cd}$ passou de 57 para 493 e de 6 para $122 \mu \mathrm{g} \mathrm{g}^{-1}$ de matéria seca nas raízes e parte aérea, entre os períodos experimentais de 12 horas e 10 dias, respectivamente, sem manifestação de danos visíveis acentuados nas plantas. No caso da salvínia os incrementos percentuais nos teores de $\mathrm{Cd}$ com aumento do tempo de exposição foram menores mas as plantas apresentaram sintomas visíveis de intoxicação. Elevação nos teores de $\mathrm{Cd}$ em função do aumento do tempo de exposição tem sido verificada em várias espécies vegetais, inclusive em aguapé conforme relata Ding et al., (1994).

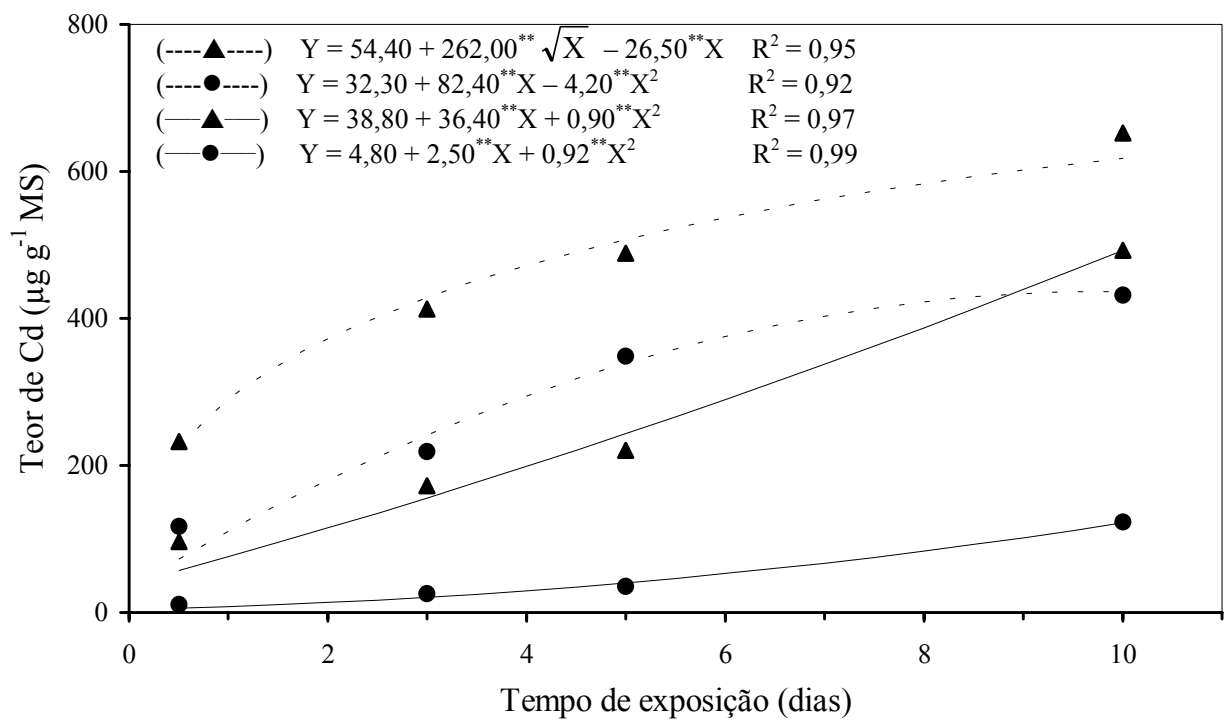

FIGURA 3 - Teor de Cd nas raízes ( $\boldsymbol{\Delta}$ ) e parte aérea ( $\bigcirc$ ) de aguapé (-) e salvínia (----) em função do tempo de exposição a uma solução de cultivo contendo $\mathrm{Cd}$ na concentração de $5 \mu \mathrm{M}$. 
Os teores de Cd elevaram-se tanto na parte aérea como nas raízes com o aumento da concentração deste elemento na solução nutritiva, nas duas espécies de plantas (Figura 4). Os teores de $\mathrm{Cd}$ nas raízes foram sempre maiores do que na parte aérea, nas duas espécies, e as diferenças mantiveram-se essencialmente constante com o aumento da concentração do $\mathrm{Cd}$ no meio de cultivo. Em concentrações de $\mathrm{Cd}$ acima de $10 \mu \mathrm{M}$, ao que tudo indica, deve ter ocorrido saturação dos sítios de ligação desse metal nas raízes de aguapé, uma vez que o incremento no teor de $\mathrm{Cd}$ nesta parte da planta foi de apenas 7,3\% para um aumento de duas vezes na concentração deste elemento na solução nutritiva. Na parte aérea, não se observou tendência à estabilização, mesmo na dose de $20 \mu \mathrm{M}$ de $\mathrm{Cd}$, embora o incremento tenha sido bastante inferior ao de salvínia. Nas plantas desta espécie, ao contrário, o teor de Cd elevou-se proporcionalmente com o aumento das concentrações de $\mathrm{Cd}$ na solução de cultivo, tanto nas "raízes" como na parte aérea ao longo de todo o intervalo de concentração testado, indicando uma incapacidade desta espécie de controlar a absorção e o acúmulo do $\mathrm{Cd}$.
$\mathrm{O}$ maior acúmulo de $\mathrm{Cd}$ nas raízes, observado nas duas espécies parece ser resultado do contato direto das raízes com a solução nutritiva e à ligação do $\mathrm{Cd}$ às cargas negativas das paredes celulares do sistema radicular em detrimento de uma maior absorção e, posterior transferência para a parte aérea (Grant et al., 1998). Adicionalmente, admite-se que parte do $\mathrm{Cd}$ absorvido é complexado na forma fitoquelatinas e armazenado nos vacúolos das células das raízes (Zenk, 1997).

Em aguapé acima de $80 \%$ de todo o $\mathrm{Cd}$ absorvido acumulou-se nas raízes, independente de se ter ou não permitido o contato das folhas com a solução nutritiva (Tabela 3). Em salvínia, entretanto, quando se permitiu que as folhas contatassem a solução de cultivo, verificou-se expressiva participação dessa parte da planta na absorção e no acúmulo do Cd. Este maior acúmulo de Cd na parte aérea resultou no aparecimento de sintomas de toxidez de Cd. Quando se impediu fisicamente o contato das folhas com a solução nutritiva o acúmulo percentual de $\mathrm{Cd}$ na parte aérea ficou cerca de 3 vezes menor, enquanto a distribuição deste elemento passou a ser essencialmente similar à observada em aguapé.

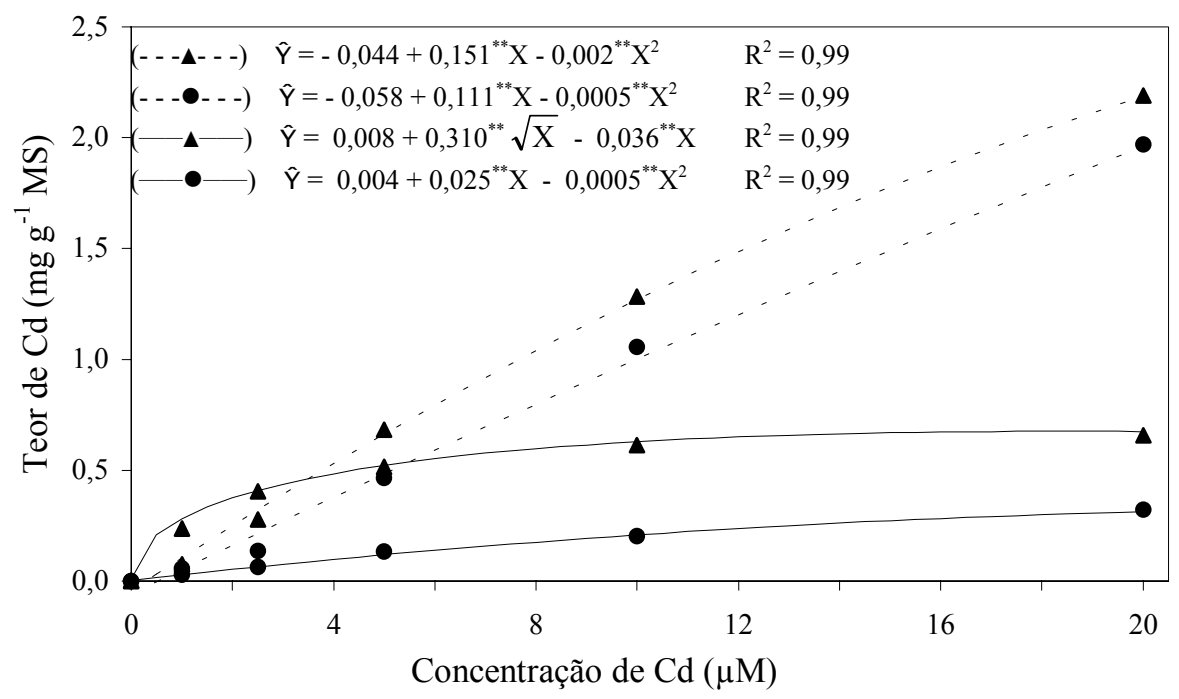

FIGURA 4 - Teor de Cd nas raízes ( $\boldsymbol{\Delta}$ ) e parte aérea ( $\bullet$ ) de aguapé (-) e salvínia (----), em função de concentrações crescentes de Cd na solução de cultivo, durante 10 dias de exposição. 
Oliveira et al.

Além disso, sob esta condição experimental, a intensidade dos sintomas de toxidez foi muito menor do que nas plantas em que se permitiu o contato das folhas com a solução de cultivo. Os resultados indicam que em salvínia, sob condições naturais, há um íntimo contato da face adaxial das folhas com a solução de nutritiva permitindo uma significativa absorção foliar.

\section{Efeito do Cd sobre a taxa de crescimento relativo}

As taxas de crescimento relativo decresceram intensamente com o aumento da concentração de $\mathrm{Cd}$ na solução nutritiva nas duas espécies aquáticas, especialmente em salvínia (Figura 5).

TABELA 3 - Distribuição percentual do Cd acumulado nas duas partes das plantas de aguapé e salvínia, permitindo-se ou não o contato das folhas com a solução de absorção, após três dias de exposição.

\begin{tabular}{|c|c|c|c|c|}
\hline \multirow{2}{*}{$\begin{array}{l}\text { Contato das folhas } \\
\text { com a solução de } \\
\text { absorção }\end{array}$} & \multicolumn{2}{|c|}{ Aguapé } & \multicolumn{2}{|c|}{ Salvínia } \\
\hline & Raízes & Parte aérea & "Raízes" & Parte aérea \\
\hline & & & & \\
\hline Sim & $83,1 \mathrm{Aa}^{1}$ & $16,9 \mathrm{Ab}$ & $53,1 \mathrm{Ab}$ & 46,9 Aa \\
\hline Não & $82,5 \mathrm{Aa}$ & $17,5 \mathrm{Aa}$ & $84,2 \mathrm{Ba}$ & $15,8 \mathrm{Ba}$ \\
\hline
\end{tabular}

${ }^{1}$ As médias seguidas pelas mesmas letras maiúsculas nas colunas, para cada parte da planta, e minúsculas nas linhas, entre espécies para cada tratamento e parte da planta, não diferem estatisticamente entre si, pelo teste $\mathrm{F}$, a $5 \%$ de probabilidade.

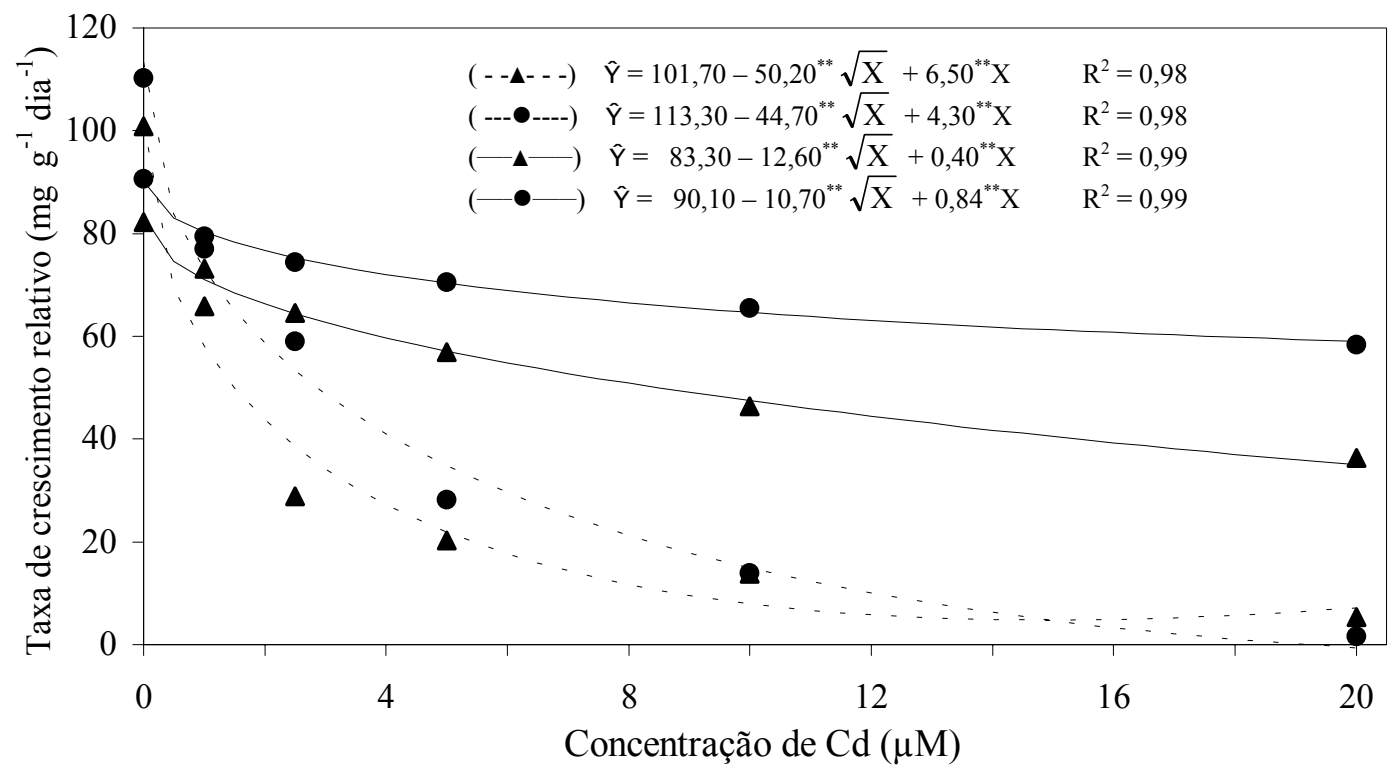

FIGURA 5 - Efeito de concentrações crescentes de Cd sobre a taxa de crescimento relativo de raízes ( $\mathbf{\Delta})$ e da parte aérea ( $\mathbf{O}$ ) de aguapé (-) e salvínia (----), durante 10 dias de exposição. 
As concentrações de Cd necessárias para uma redução de $25 \%$ no crescimento relativo foram de $3,1 \mu \mathrm{M}$ para as raízes e de $7,1 \mu \mathrm{M}$ para a parte aérea de aguapé e de $0,3 \mu \mathrm{M}$ para as "raízes" e de $0,5 \mu \mathrm{M}$ para as folhas de salvínia, o que torna claro a maior sensibilidade da salvínia a este metal. As raízes, possivelmente por constituir a parte da planta que está diretamente em contato com o metal pesado, foi a parte da planta, tanto em aguapé como em salvínia, que apresentou os teores mais elevados de Cd (Figura 3 e 4), o que pode explicar a maior diminuição na taxa de crescimento relativo nessa parte da planta. Além disso, em aguapé, talvez porque as folhas tiveram menor contato com a solução nutritiva, a absorção de $\mathrm{Cd}$ ocorreu essencialmente pelas raízes, resultando numa diferença mais acentuada entre as partes da planta, do que em salvínia

Uma análise de correlação entre as concentrações de $\mathrm{Cd}$ nas raízes e na parte aérea e as respectivas taxas de crescimento relativo, mostrou os seguintes coeficientes de correlação: 0,91 e $-0,81$ para raiz e parte aérea de aguapé, respectivamente, e $-0,72$ e $-0,78$ para raiz e parte aérea de salvínia, respectivamente, todos significativos. Isto indica que a redução da taxa de crescimento relativo, provavelmente, se deveu ao aumento na concentração e na toxicidade do $\mathrm{Cd}$ nesses tecidos vegetais.

As plantas de aguapé não apresentaram sintomas visíveis de toxidez ou qualquer outra indicação de que o metabolismo vegetal estivesse sendo alterado, nas concentrações mais baixas de $\mathrm{Cd}$. Nas concentrações mais elevadas, os sintomas de toxidez mais comumente observados foram acúmulo de antocianinas nos pecíolos e estolões, clorose internerval nas folhas e escurecimento acentuado das raízes, além de redução na emissão de novas raízes e folhas. Esses sintomas, entretanto, não são considerados específicos para toxidez de $\mathrm{Cd}$, uma vez que várias deficiências minerais podem resultar em sintomatologia similar (Newman e Haller, 1988). Em salvínia, escurecimento de folhas e "raízes" e inibição da formação de novas plantas tornaram-se facilmente visíveis, já a partir do segundo dia, nas concentrações de 10 e $20 \mu \mathrm{M}$ de $\mathrm{Cd}$ e, a partir do quinto dia, na concentração de $1 \mu \mathrm{M}$ de Cd. Altas concentrações de $\mathrm{Cd}$ resultaram em inibição do crescimento, engrossamento e encurtamento das raízes (Breckle, 1991).

Em salvínia, a partir de concentrações de Cd de $5 \mu \mathrm{M}$, já se observava um decréscimo significativo na capacidade de sobrevivência das plantas. Em soluções nutritivas com 10 e $20 \mu \mathrm{M}$ de Cd foram observadas cerca de 60 e $100 \%$ de morte das plantas, respectivamente. Em aguapé, mesmo no nível mais elevado de $\mathrm{Cd}$ não foi observada morte de nenhuma planta.

A exposição de plantas a níveis tóxicos de Cd durante períodos de tempo relativamente longos (cinco ou mais dias), como os utilizados neste experimento, resulta, quase sempre, em forte interferência sobre o crescimento das plantas. É que, sob tais condições a síntese de compostos ricos em grupos tiol, que poderiam complexar e impedir a ação do metal, cai rapidamente (Ding et al., 1994). O Cd, então, provoca decréscimo da fotossíntese, redução na absorção e no transporte de nutrientes (Larsson et al., 1998), danos às membranas, distúrbios hormonais e alteração na atividade de várias enzimas (Barceló e Poschenrieder, 1990), resultando em eventual morte das plantas, como se observou neste experimento, especialmente em salvínia.

\section{AGRADECIMENTOS}

Os autores agradecem ao $\mathrm{CNPq}$ pelas bolsas de pesquisa e à FAPEMIG pelo auxílio financeiro concedido ao Projeto (CBS 2242/97).

\section{REFERÊNCIAS}

ALLAN, J.E. The preparation of agricultural samples for analysis by atomic absorption spectrometry. Varian Techtron, 1969. 15 p. (Bulletin 12/69).

BARCELÓ, J. \& POSCHENRIEDER, C. Plant water relations as affected by heavy metal stress: a review. Journal of Plant Nutrition, 13:1-37, 1990. 
BRECKLE, S.W. Growth under stress. Heavy metals. In: WAISEL, Y., ESHEL, A, KAFKAFI, U. (Eds.). The Plant Roots, the Hidden Half. New York, Marcel Dekker, 1991. p.351-73.

CAKMAK, I.; WELCH, R.M.; HART, J.; NORVELL, W.A.; OZTURK, L. \& KOCHIAN, L.V. Uptake and retranslocation of leaf-applied cadmium $\left({ }^{109} \mathrm{Cd}\right)$ in diploid, tetraploid and hexaploid wheats. Journal of Experimental Botany, 51:221-226, 2000.

DING, X.; JIANG, J.; WANG, Y.; WANG, W. \& RU, B. Bioconcentration of cadmium in water hyacinth (Eichhornia crassipes) in relation to thiol group content. Environmental Pollution, 84:93-96, 1994.

FETT, J.P.; CAMBRAIA, J.; OLIVA, M.A. \& JORDÃO, C.P. Absorption and distribution of cadmium in water hyacinth plants. Journal of Plant Nutrition, 17:1219-1230, 1994.

FUJITA, M. \& KAWANISHI, T. Purification and characterization of a Cd-binding complex from the root tissue of water hyacinth cultivated in a $\mathrm{Cd}^{2+}$-containing medium. Plant and Cell Physiology, 27:1317-1325, 1986.

GRANT, C.A.; BUCKLEY, W.T.; BAILEY, L.D. \& SELLES, F. Cadmium accumulation in crops. Canadian Journal of Plant Science, 78:1-17, 1998.

GUPTA, M. \& DEVI, S. Cadmium sensitivity inducing structural responses in Salvinia molesta Mitchell. Bulletin of Environmental Contamination and Toxicology, 49:436-443, 1992.

HART, J.J.; WELCH, R.M.; NORVELL, W.A.; SULLIVAN, L.A. \& KOCHIAN, L.V. Characterization of cadmium binding, uptake, and translocation in intact seedlings of bread and durum wheat cultivars. Plant Physiology, 116:1413-1420. 1998.
HOAGLAND, D.R. \& ARNON, D.I. The waterculture method for growing plants without soil. California Agricultural Experiment Station, 1950. 39 p. (Bulletin 347)

HUNT, R. Plant growth analysis. London, Edward Arnold Limited, 1978. 67 p.

LARSSON, E.L.; BORNMAN, J.F. \& ASP, H. Influence of UV-B radiation and $\mathrm{Cd}^{2+}$ on chlorophyll fluorescence, growth and nutrient content in Brassica napus. Journal of Experimental Botany, 49:1031-1039, 1998.

MURAMOTO, S. \& OKI, Y. Removal of some heavy metals from polluted water by water hyacinth. Bulletin of Environmental Contamination and Toxicology, 30:170-177, 1983.

NEWMAN, S. \& HALLER, W.T. Mineral deficiency symptoms of water hyacinths. Journal of Aquatic Plant Management, 26:55-58. 1988.

OBATA, H. \& UMEBAYASHI, M. Characterization of cadmium-binding complexes from the roots of cadmium-treated rice plant. Soil Science and Plant Nutrition, 32:461-467, 1986.

OUTRIDGE, P.M. \& HUTCHINSON, T.C. Effects of cadmium on integration and resource allocation in the clonal fern Salvinia molesta. Oecologia, 84:215-223, 1990.

OUTRIDGE, P.M.; RAUSER, W.E. \& HUTCHINSON, T. C. Changes in metalbinding peptides due to acclimation to cadmium transferred between ramets of Salvinia minima. Oecologia, 88:109-115, 1991.

RAUSER, W.E. The amount of cadmium associated with Cd-binding protein in roots of Agrotis gigantea, maize and tomato. Plant Science, 43:85-91, 1986. 
RUIZ, H.A. Estimativa dos parâmetros cinéticos $\mathrm{Km}$ e Vmax por uma aproximação gráficomatemática. Revista Ceres, 32:79-84, 1985.
ZENK, M. H. Heavy metal detoxification in higher plants - a review. Gene, 179:21-30, 1997. 